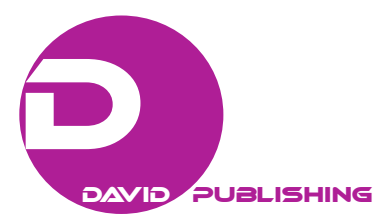

\title{
Study on University Ecosystem in the High-Tech Context*
}

\author{
Wang Yuqiu \\ Linyi University, Linyi, China
}

\begin{abstract}
The university ecosystem highlights the systematic designing and the integrative, self-adaptive mechanism to promote economic prosperity and social cohesion. The infrastructure, curriculum, faculty, resources, etc. should be designed systematically and self-adjust dynamically in the context of high technology. The interaction and coordinating of the internal and external factors and the dynamic co-evolving mechanism between different sectors as university, enterprise, and government should be considered about with the precisely positioning of human resources, capability, and requirements. Educate for excellence is the standard for all universities. The integrative paradigm between disciplinaries, knowledge and application, university and society, the diversity of students should be enhanced. The construction of smart city, the platform, the learning community, the students' entrepreneur union, the spin-offs can act as media to link knowledge and society.
\end{abstract}

Keywords: university ecosystem, consistency and cohesion, integrative, self-adaptive, high technology

\section{Introduction}

University takes the primary responsibility to preserve civilization, to produce knowledge, and to educate young generations for the economic prosperity and social cohesion. University in China can be divided into: the top university (which highlights academic training, top research, and initiative projects, e.g., the 112 "Project 211" universities and 39 "Project 985" universities), the entrepreneurial university (which highlights knowledge application and service for the local society), and the general university (which is between the top university and the entrepreneurship university considering the academic rigor and performance as well as the educational modes). Different category of university has different mission and features, while government's investment is much different, too. From 2009 to 2013, the total government research funding for “Project 985” universities (total 39 institutions) is 13.9 billion RMB, and "Project 211" universities (total 73 institutions) approximately 5.1 billion RMB and the rest of 670 common undergraduate universities only 7.9 billion RMB. While the research performance of the top universities and their contribution to science discovery, innovation, and employment rate are not optimism.

Investment in education accounts for about 4\% of total gross domestic product (GDP) in China in 2015. Although the number of university and student has been increasing greatly, there are some serious concerns about the quality of education. One study estimates that only 1.2 million of 15.7 million university graduates (or 7.6\%) have skills that are valued by international markets for human capital. In other words, the majority of students educated in China universities do not have adequate skills or competency for high quality jobs.

\footnotetext{
*Acknowledgement: The paper was funded by the Doctoral Scientific Research Foundation of Linyi University (No. 4313031): Science, Democracy, and Freedom; Philosophy \& Social Science Project of Linyi University (No. 15LUZS08, 2015); Social Science Fund Entrepreneurship Project of Shandong Province (No. 16SYB004).

Wang Yuqiu, Ed.D., professor, Department of Educational Administration, School of Education, Linyi University.
} 
From the 1980's on, Chinese higher education has undergone a series of reforms which give university more flexibility and autonomy, but the bureaucracy system leads to lots of conflicts and excessive departmentalization, segmentation, and over specialization. Various "powers" dominate the community. Curriculum, teaching, research, application are not seamlessly integrated. There are conflicts between policies, institutions, and systems. It is lack of efficient translating mechanism between knowledge and application. The effective financial collaborating mechanism for research, development, and transferring has not formed. University must meet with various demands from a multiple groups—students, staff, governments, employers, research councils, sponsors, etc.. These demands require changes in policy, practice, systems, and culture. Of course, the government and industry should take the responsibility, too.

In the context of high technology, university and society are experiencing radical transition. This change has significant implications for curriculum, teaching, and management. The ability to generate, collect, process, and explore big data by industry, academy, and government promotes democracy and equality. Simulating manufacturing and decision-making can avoid much risk and reduce cost. Big data mining and analysis technology creates better products, gets greater insights, and gain competitive advantage over traditional development processes. In the context of high technology, we can make good use of big data techniques for statistics and metrics study, using sensor collecting data and visualization, simulating, and the geographic information system (GIS) techniques to position precisely, monitor, evaluate, and make strategic plan. We can consider and design the regional and national higher education structure and system in the context of globalization and highlights the interaction between top research, technology development, and application.

\section{Literature}

Chinese scholars have studied the university system and elements in detail and pointed out some core elements and the integrative mechanism. For example, Zhao (2003) proposed five core components of university innovation system: the infrastructural system, developing platform, intermediary system, public service platform, and culture construction. These elements interact with each other and form a integrative system.

Yuan and Jiang (2007) studied the construction of university innovation system and pointed out that university should deploy the resources rationally and strengthen the initiative innovation, knowledge base construction, integrate scientific and technological resources, and optimize the efficiency.

Liu (2011) studied the reconstruction of the undergraduate education in American top universities and found that they highlight such aspects in undergraduate education: educate leaders for the future, to construct knowledge base, enhance top research and publication, to build expertise system and regional networks to promote learning society. The undergraduate reform projects include evaluation, cooperative learning, first-year experience, liberal education, interdisciplinary programs, science education, learning service, teacher training, teaching innovation, and undergraduate research.

Yuan and Peter (2013) studied the spiral transformation of knowledge innovation under WEB 2.0 and put forward the socialization and externalization-internalization and externalization-combination and internalization (SE-IE-CI) model. Zhao (2013) studied the development of higher education quality index based on cloud computing and big data, the technology, theory and mechanism, and highlighted the construction of data systems, respect of data rights and obligations. 
University innovation highlights the basic research and technology innovations which link the relevant organizations across universities, enterprises, government, finance, and the intermediary organizations. University is in the upstream along the whole innovational value chain. And in the high technology background, university should enhance knowledge producing and disseminating, construct knowledge base and platform, enhance open access and learning service, and integrate university with society.

\section{Some New Trends}

Study on the integration of high technology in higher education. Various hardware and software tools are used to facilitate teaching and learning. High technology are integrated in the infrastructure, instructional design, communicating and interaction, monitoring and evaluation.

Study on the ecosystem of university with the local society. The innovation capabilities of region originate from the global network of collective intelligence. The social networks also provide a new way for knowledge transfer and spillover. Universities tend to integrate with the local society, the agility workshop, and spin-offs assemble around the residential area with population diversity.

Study on the values of university using both empirical data and theory to address values in teaching, research, and management spectrum. Values in teaching, research, and management should be aware of by university teachers, leadership, and managers, as well as students and customers. Teaching with values and for values in all subjects has the potential to radically alter students' experience and improve quality, competency.

\section{Case Study}

Case study one. In 2004, the British government published a 10-year investment framework for science and innovation. The purpose is to promote outstanding scientific and technological discovery and to turn knowledge into new products and services. In order to maintain and develop world-class excellence and core strengths, a culture of multidisciplinary research and the underpinning infrastructure and funding mechanism to support it are taken into account. They set out plans to drive up the numbers of skilled scientists and engineers, to put the science based on a sound financial footing through better financial management and investment in infrastructure, to support business research and development, to make the best of research across government and translate this knowledge more effectively into business and public service innovation, to strengthen the link between the world of knowledge and the world of labor, and to reallocate the faculty human resource to match the requirement.

Since 2012, government has invested over $£ 400$ million to equip the United Kingdom (UK) researchers in academia and industry to meet high-tech challenge and take advantage of the opportunities. Centers of expertise have been established, new training courses have been designed to equip researchers for this new era of data driven discovery, and the department of business, innovation and skills (BIS) has published the UK's Data Capability Strategy. Most recently, funding for the Alan Turing Institute was announced for research into the underpinning mathematics and algorithms for advanced high performance computing (HPC) modeling and simulation (see Figures 1 \& 2). All these policy and measures have significant implication for university. University must take the responsibility to carry out excellent research and be adapt to the high-tech requirement. Research paradigm, curriculum, and teaching modes must shift accordingly.

Case study two. In 2014, Brookings published the metropolitan program-The rise of innovation districts: A new geography of innovation in America, in which the authors pointed out that for the past 50 years, the 
landscape of innovation has been dominated by places like silicon valley, which are isolated campuses within suburban areas. A new complementary urban model is now emerging, giving rise to what we are calling "innovation district." The new geography of innovation set within downtown areas that allow firms and talented people to congregate together in dense and amenity rich urban environments. In doing so, firms and workers are better able to interact, share ideas, and practice "open innovation," all within a vibrant mixed-use environment that appeals to urban workers. The new trend is to nurture living, breathing communities rather than sterile remote, compounds of research silos.

Given the shifting spatial geography of innovation, the federal government and states is considering about locating new or existing advanced research facilities in innovation districts. The shifting of public university advanced research facilities to innovation districts has become a recognized trend. In the next decade, states in particular would rethink the location of the research arms of institutions of higher learning to spur market creation. A more integrative ecosystem with university, innovation district, and community ecosystem is forming. University should adjust the strategy according to the environment to drive innovation, to promote social cohesion, and to push forward the learning society. Local institutional capital is also being unlocked to spur urban regeneration. Massachusetts Institute of Technology (MIT), for example, has used its extensive land holdings in Cambridge to spur the development of research, entrepreneurial, commercial, office, and residential space.

One strategy a few practitioners are applying is to focus on the many innovation jobs (e.g., lab technicians) that require customized technical training in high schools or community colleges, rather than a four-year or advanced college degree. In fact, in mature science and research parks, the conventional wisdom is that $40 \%$ of the jobs require high school diplomas or associate degrees, $40 \%$ requiring bachelor degrees, and only $20 \%$ requiring master and Ph.D. degrees.

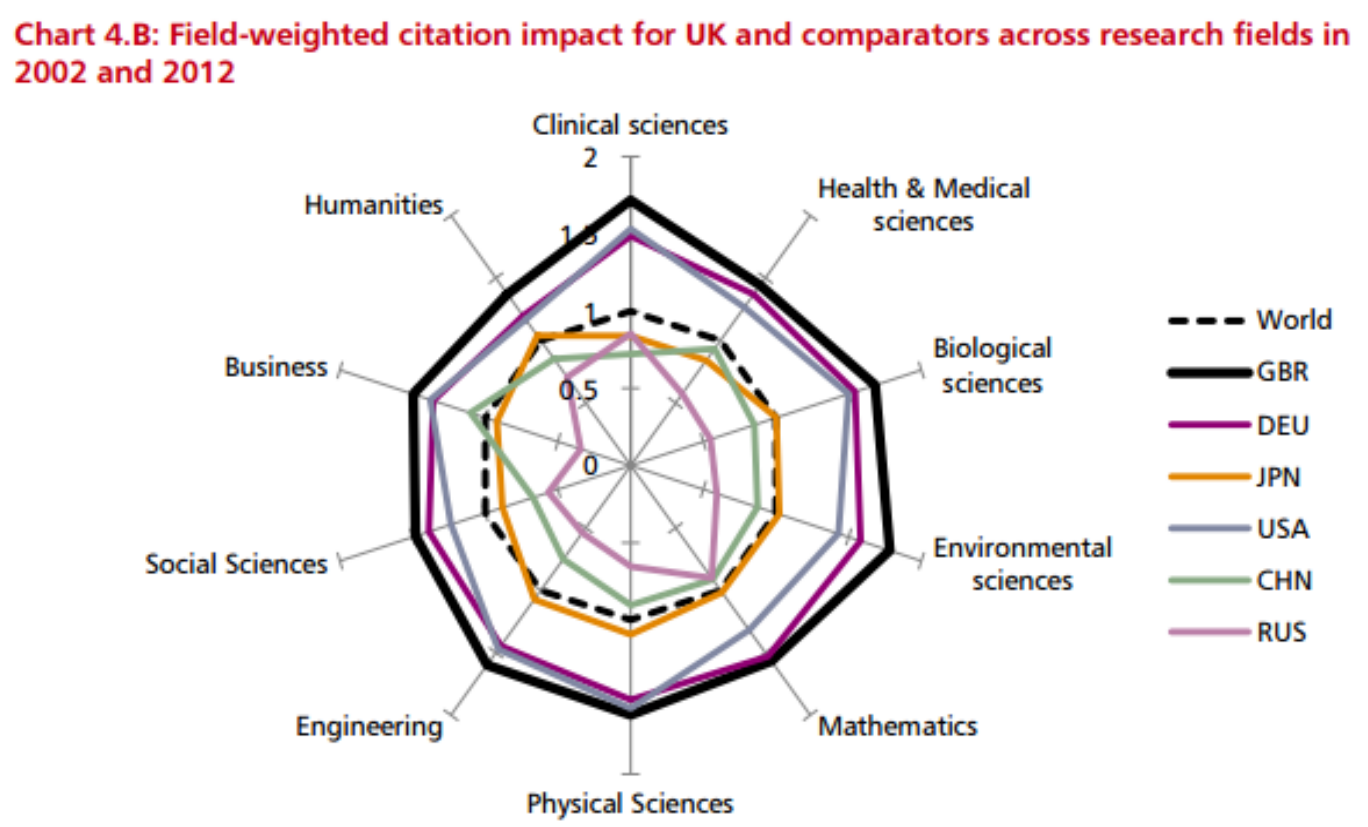

Source: Elsevier (2013)

Figure 1. Field-weighted citation comparation in 2002 and 2012. 


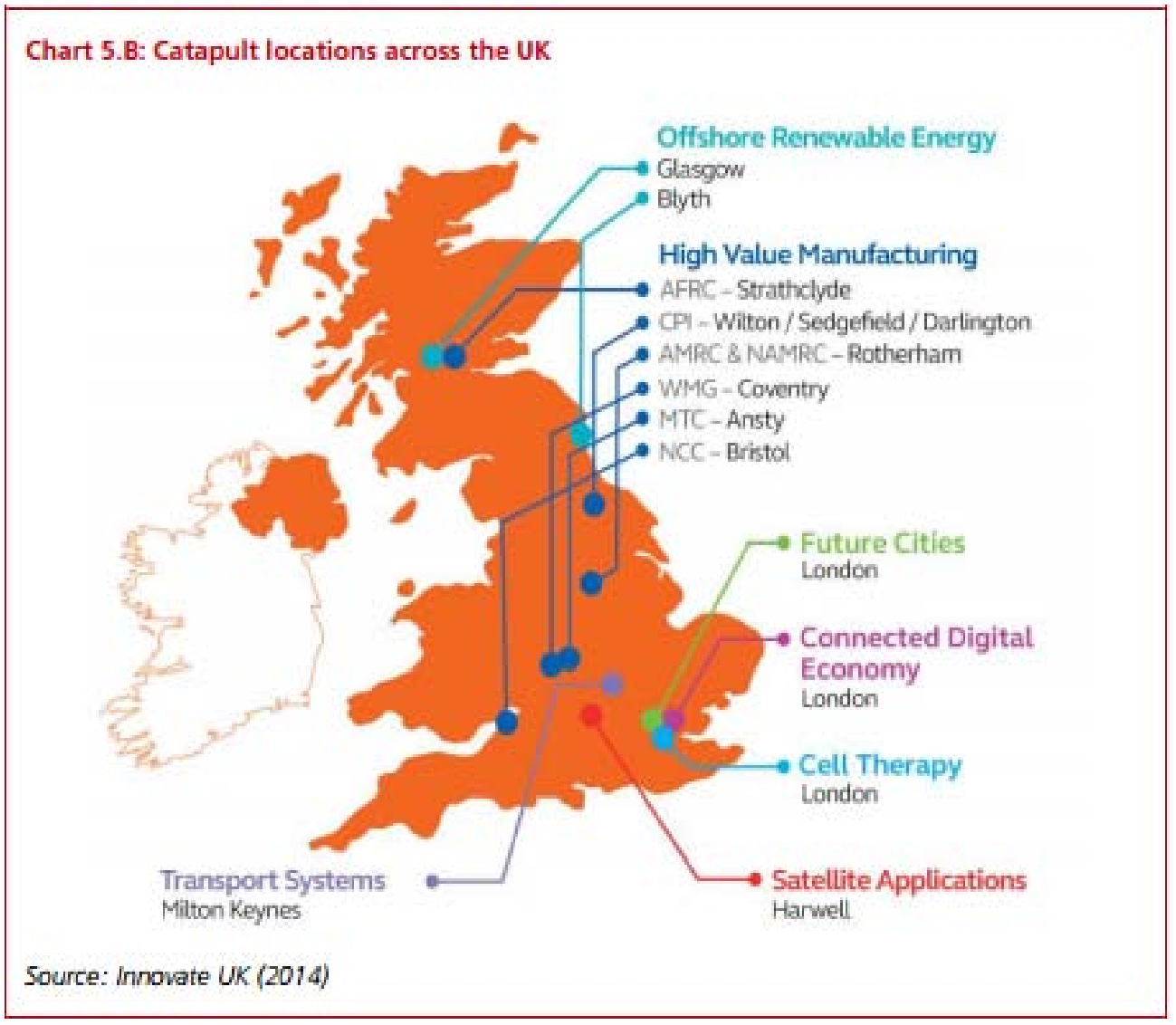

Figure 2. Catapult location across the UK.

\section{Findings and Suggestions}

\section{Highlight Different Strategy for Different University and the Integrative Mechanism}

Different kind of university has different context, culture, and missions. The research university emphasizes on the elite cultivating and nurturing, the cutting edge research, and the outstanding projects. The entrepreneurship university strengthens the link between science, technology and society, knowledge and application. Accordingly, different curriculum and teaching modes are selected. The research university should preserve and exercise scientific rigor and originality, in a spirit of impartiality and ethics. Academic authority should be empowered and take the responsibility for monitoring evaluation based on the rigid science and professional criteria and evidences. The external assessment is also necessary, which is usually carried out by government, industry sectors, community, and research sponsors.

No matter what kind of university, the following qualities for graduates are highlighted: integrity, resilience, creativity, initiative, confident, humanity, value, ethics, and autonomy. The differences lie in knowledge, skills, competency and learning strategy, the width and depth, and the methodology and objectives. University culture, especially the tacit knowledge and cognitive learning strategy cannot be duplicated or transacted.

Considering the funds for research, the top universities get major funds from government, and the alumni donation, the charity, the collaborating fund, the World Bank, and the United Nations Educational, Scientific, and Cultural Organization (UNESCO) also play important roles. The entrepreneurship universities get fewer 
funds from government, but could change the strategy to seek for funds from financial agency or the mediate agency, as well as the collaborating project with enterprises, local society and government and get "win-win" effect. Investment councils will work with universities, investors, and enterprises to promote collaboration across institutional boundaries and link teaching, research, and application (see Figure 3).

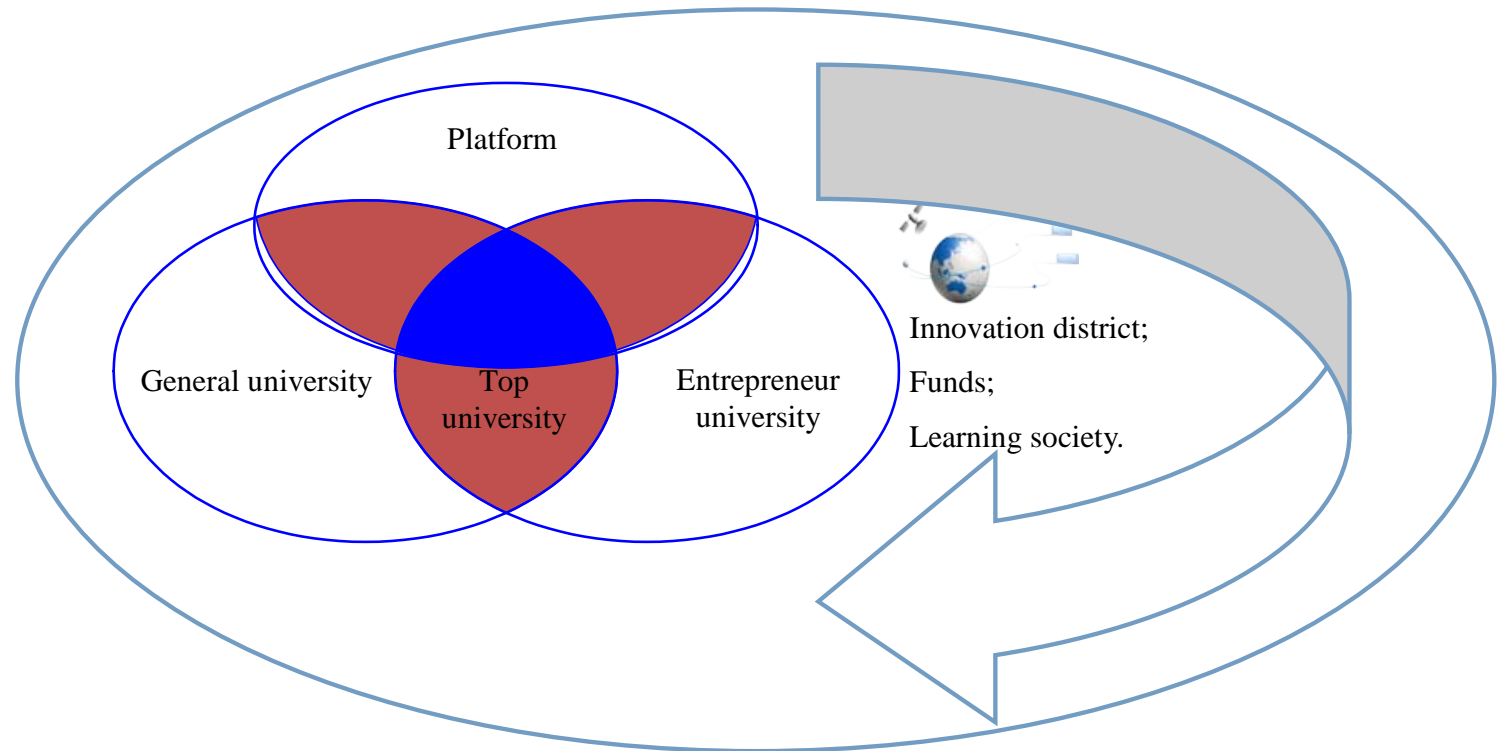

Figure 3. University ecosystem and the integrative model.

\section{Integrate High Technology in University System and Practice}

High technology, especially the informational technology, such as big data, visualization, and simulation technology should be integrated in university teaching, research, and management. For example, we can use artificial intelligent for classroom teaching assessment to precisely monitor the teaching efficiency and students' learning preference and difficulties. We can use massive online curriculum to share excellent teaching resources world-wide. We can use simulation technology for product-designing, risk-evaluation, doing experiment, and professional skills training. We can also use big data mining and analyzing techniques to map the research and innovation scenario and to predict tendency dynamically. We can use big data, visualization, and simulation technology to make decision from macro to micro dimensions. We can use geography information system to illustrate resources and environment and to make strategy plan, or to make decision which university to choose, etc.

University infrastructure, facilities, smart campus, and data base should be budgeted and audited to maximize the efficiency. Knowledge resources and laboratory should be open to students, local community, enterprises, and government, which will shrink the data gap between different groups from different sectors. Continuous collaborative research and development program and knowledge transfer networks will be built.

\section{Keep Balance of Efficiency and Quality With Self-Adaptive Mechanism}

There are some paradoxes in education system and management, such as quality and efficiency, cost and profit, scale and quality, elite and democracy, etc.. How to keep balance, promote overall development, and form a ecosystem? With the help of big data, simulating and visualization technology, and open access and massive online curriculum, we can shrink the gap and keep balance dynamically, embracing the learning society. The traditional triangle chain model is as below (see Figure 4). 


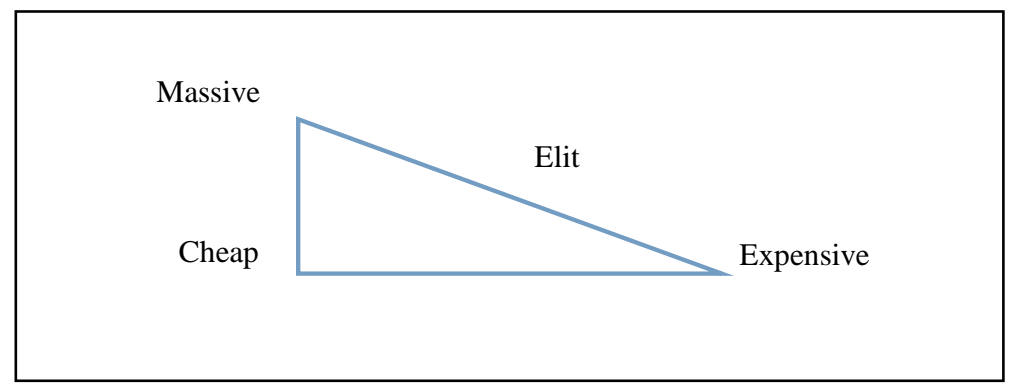

Figure 4. The balance triangle.

From Figure 4, we can see the paradox: If we adopt the elite higher education strategy, only a small ration of secondary school graduates can enter university for further study and the teacher supply is sufficient, the condition is superb, the quality is excellent, but we cannot meet with the requirements of democracy and development. If we advocate the popularity of higher education and expand the university scale, the price and cost will be cheaper to satisfy with the large quantity of enrollments and the diversity of students, while the quality will probably decline, in that case we need more space to hold to the students, we need more infrastructure and facility, as well as more qualified teachers. But the teacher supplying is limited and our national investment is restricted to GDP and development strategy, so we have to hire some unqualified teachers and the infrastructure cannot meet with the development of high technology. Now, we have to think: How to get out of the paradox with the help of high technology in the global context?

The co-evolving model is our best choice that is to enhance interaction among university unions, between university-government-industry and the public society and share good idea, knowledge, and technology. Different sectors and diverse population should keep harmony with the basic value identity, such as empathy, integrity, resilience, and respect, and reciprocal and environmental awareness must be respected by all. Then, we can use the diversity as resources to form an ecosystem. Then, various classification of university with different advantages and disadvantages can coordinate with each other. The university, the innovation district, and the local society should integrate for convenience. The internal tension and external interacting mechanism should be taken into account. The balance triangle will shift to topology form with self-adaptive mechanism in an open complex system (see Figure 5).

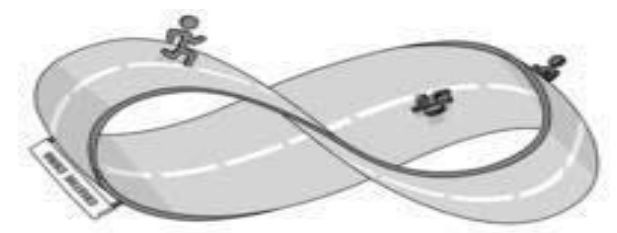

Figure 5. The co-evolving mechanism of university.

\section{Enhance International Education for "Win-Win"}

Western education will likely remain the leading choice for Chinese students due to its cross-disciplinary programs and encourage critical thinking, respect diversity of students' needs and potential, and provide more opportunities for students to participate in activities, project and meet with academic and high technology challenges. Meanwhile, the international students have enrolled in over 775 higher education institutions in China. Until 2014, there were more than 377,000 foreign students from 203 countries or regions studying in China. 
The "brain circulation" emphasizes on human capital circulation across nations in the global market and obtains a "win-win" effect. It is considered a two-way flow of skill, capital, and technology, unlike brain drain and reverse brain drain. High-skilled migration brings important economic benefits and fills the critical technological gaps. The cross national companies take the advantages of worldwide research resources and attract globally dispersed scarcity of top talents.

To reverse the "brain drain" ditch, the less-developed or developing nations can select top students to go aboard for further study and come back to initiate a new enterprise. The government can provide rewards or funds for those brain gains, implementing new contracts. These brain gains also act as bridges for foreign investment and trade and promote the transfer and dissemination of knowledge and technology. A reciprocity and trust relationship will be established in the cooperation and a win-win effect will be gotten both in academic and economic fields. The International Corporation, projects, visiting scholars, international conference, and academic associations will play important roles in promoting knowledge producing, diffusion, and the coming of learning society. Accordingly, to develop international standards in industry, knowledge, technology, profession, and business ethics is in need.

\section{Consider Diversity of Students and Promote Equality}

Considering equality of education supplying, the inclusive idea and strategy must be harnessed. We can tailor our curriculum and choose proper teaching material and methods for diversity groups, e.g., the international students, the students at risk, the students from lower social-economic group, the male learners, mature students, care leavers and students with special needs, the disabilities, as well as the gift students and the normal students. With the application of computer aid instruction (CAI), we can support students by some software, such as the learning skills improvement service (LSIS). New interactive software enables male learners and disabled students to be engaged and makes the diversity of students as a source of learning in the learning community (e.g., peer support).

\section{Enhance Eco-System of University, Innovation Districts and the Local Society}

University would integrate with the innovation districts and local society and offer advanced facilities, knowledge resources, and consulting service. The social-technology-society (STS) program, the entrepreneur union, the network community, and the spin-offs can act as "bridges" to integrate university with innovation districts. The open access of data-base, the real-time interactive platform, and the massive on-line courses promote knowledge share, spillover, and transmitting to embrace the learning society (see Figure 6).

\section{Conclusion}

In the global and high-tech driven era, university should promote change and be adapt to change actively, and play a key role in knowledge producing, sharing, and converting to promote economic prosperity and social cohesion, highlight the integration of high technology with teaching, research, and management activities and the integration of university with the innovation district and local society, to form an ecosystem of diversity population, rural and urban, knowledge and application, industry and service system. University should improve teaching, research, and management to create and disseminate values, to construct knowledge platform and open intellectual resources to the public, and to advocate equality opportunities for rural and urban society and to promote the learning society. 


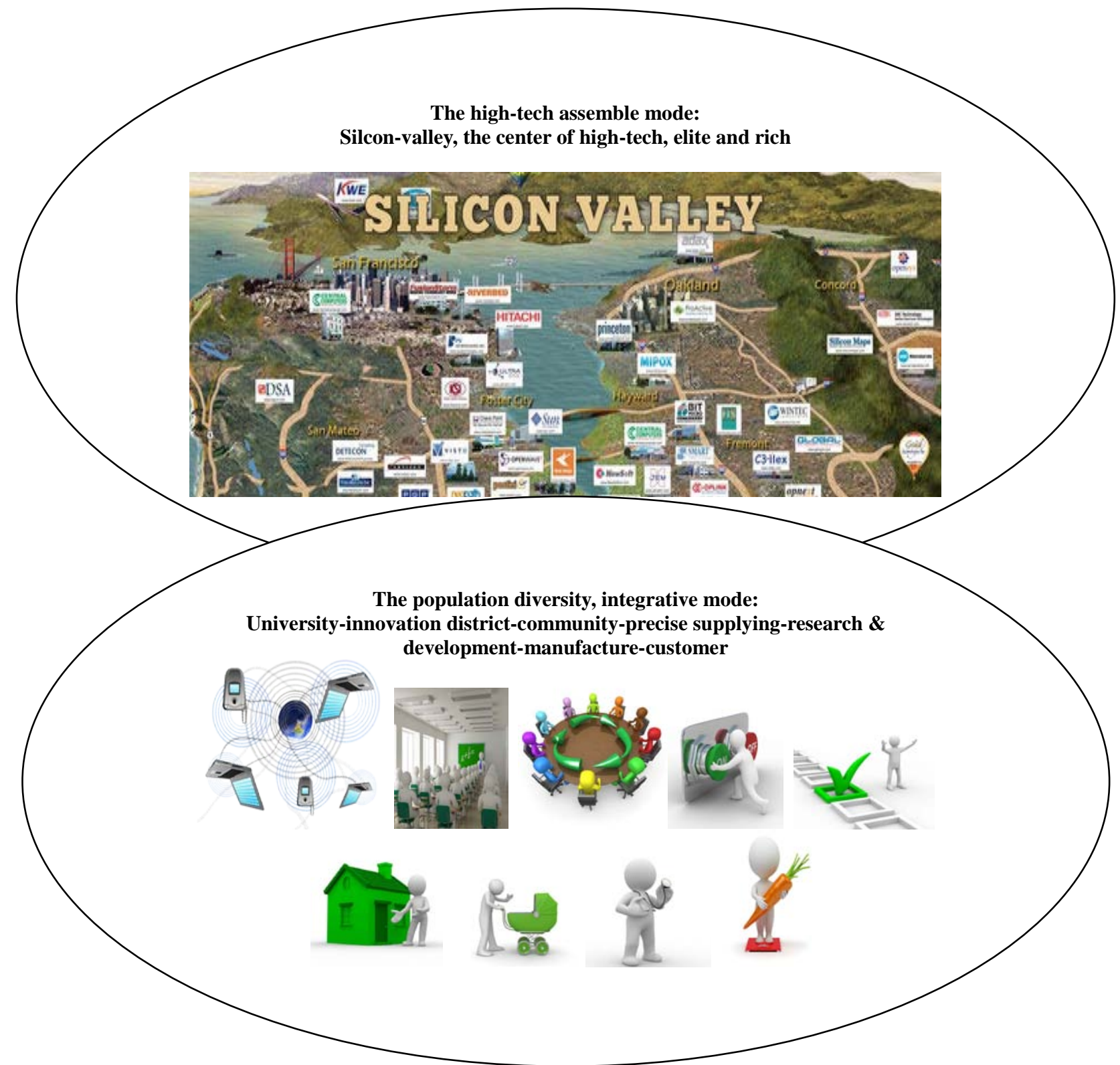

Figure 6. The university ecosystem and self-adaptive mechanism.

\section{References}

China Education Center Ltd.. (2016). Project 211 and 985. Retrieved from http://www.chinaeducenter.com/en/

Department of Trade and Industry, HM Treasury, Department for Education and Skills. (2004). Science \& innovation investment framework (2004-2014). Retrieved from https://www.gov.uk/government/publications

Farrell, D., \& Grant, A. (October, 2005). Addressing China's looming talent shortage. McKinsey \& Company. Retrieved from http://www.mckinsey.com/mgi/overview

Harland, T., \& Pickering, N. (2010). Values in higher education teaching. International Journal for Academic Development, 16(2), 179-181.

Katz, B., \& Wagner, J. (May 1, 2014). The rise of innovation districts: A new geography of innovation in America. Brookings Institution. Retrieved from http://www.brookings.edu/about/programs/metro/innovation-districts

Liu, B. C. (2011). Educate for leaders of future: Reconstruction of American research university undergraduate education (pp. 58-59). Beijing, China: Higher Education Press. 
Menon, M. E., Terkla, D. G., \& Gibbs, P. (1998). Using data to improve higher education: Research, policy, and practice. Global Perspectives on Higher Education, 29, 39-63. Retrieved from https://www.sensepublishers.com/

People’s Republic of China Ministry of Education. (July 20, 2015). 2015 Chinese college graduates employment report. Retrieved from http://www.moe.edu.cn/jyb_xwfb/s5147/201507/t20150720_194510.html

Thirunarayanan, M. O., \& Pérezprado, A. (2005). Integrating technology in higher education. Maryland, USA: University Press of America.

United Nations Educational, Scientific, and Cultural Organization (UNESCO). (1998). World declaration on higher education for the 21st century: Vision and action. Retrieved from http://www.unesco.org/education/educprog/wche/declaration_eng.htm

Yuan, M. Q., \& Jiang, L. (2007). Consideration about the construction of science and technology innovation system in college and university. Management of Technology and Innovation, 28(3), 38-4.

Yun, Q. Y., \& Gloor, P. A. (2013). Spiral transformation model of knowledge innovation under Web 2.0: SE-IE-CI model. Journal of Library Science in China, 39(204), 63-70.

Zhao, L. L. (2013). The development of higher education quality index based on cloud computing and big data-Technology, theory, and mechanism. Fudan Education Forum, 11(6), 52-57.

Zhao, X. P. (2003). Analysis of the developing trend and the strategy, to promote the construction of $S$ \& T innovation system in China. China Higher Education, (8), 3-6. 